OPEN ACCESS

Edited by: Gloria Ravegnini,

University of Bologna, Italy

Reviewed by:

Marina Pajic,

Garvan Institute of Medical Research,

Australia

Samuel J. Klempner,

Massachusetts General Hospital

Cancer Center, United States

*Correspondence:

Pashtoon Murtaza Kasi

Pashtoon-kasi@uiowa.edu

Specialty section:

This article was submitted to

Pharmacogenetics and

Pharmacogenomics,

a section of the journal

Frontiers in Pharmacology

Received: 10 October 2019

Accepted: 08 January 2020

Published: 10 February 2020

Citation:

Kamatham S, Shahjehan F and Kasi PM (2020) Circulating Tumor

DNA-Based Detection of Microsatellite

Instability and Response to Immunotherapy in Pancreatic Cancer.

Front. Pharmacol. 11:23.

doi: 10.3389/fphar.2020.00023

\section{Circulating Tumor DNA-Based Detection of Microsatellite Instability and Response to Immunotherapy in Pancreatic Cancer}

\author{
Saivaishnavi Kamatham ${ }^{1}$, Faisal Shahjehan ${ }^{2}$ and Pashtoon Murtaza Kasi ${ }^{3 *}$ \\ ${ }^{1}$ Department of Cancer Biology/Pathology, Wayne State University, Detroit, MI, United States, 2 Department of Internal \\ Medicine, Conemaugh Memorial Medical Center, Johnstown, PA, United States, ${ }^{3}$ Department of Hematology/Oncology, \\ University of lowa, lowa City, IA, United States
}

Pancreatic cancer is an aggressive malignancy with poor survival. Research has indicated the association of few genetic aberrations with pancreatic cancer. The data regarding the prevalence of microsatellite instability in pancreatic cancer is diverse and controversial. However, it could be an actionable target in pancreatic cancer especially due to availability of immune checkpoint inhibitors which has demonstrated promising results in different types of cancers. We present a case of pancreatic cancer whose microsatellite instability status was identified on liquid biopsy (circulating tumor DNA testing). Our patient showed a dramatic ongoing durable response to immunotherapy. We were able to do serial monitoring with liquid biopsy that showed clinical utility and validity.

Keywords: circulating tumor DNA, microsatellite instability, pancreatic cancer, immunotherapy, pembrolizumab

\section{BACKGROUND}

Pancreatic cancer is a challenging disease with unfavorable outcomes. Pancreatic ductal adenocarcinoma (PDAC) constitutes around 90\% of all malignant pancreatic cancers (Hackeng et al., 2016). As opposed to other common cancers, there has been a rise in incidence and mortality rates of PDAC (Ryerson et al., 2016). According to the American Cancer Society, it is the fourth leading cause of cancer-related mortality in both males and females with an estimated number of new cases and deaths in the United States in 2019 as 56,770 and 45,750, respectively (Siegel et al., 2019). PDAC is associated with poor prognosis, having a 5 -year survival rate of $8 \%$, owing to its presentation as an advanced disease, being resistant to different drug regimens and a distinct tumor microenvironment with condensed desmoplasia (Mahadevan and Von Hoff, 2007; Yachida and Iacobuzio-Donahue, 2009; Erkan et al., 2010; Erkan et al., 2012; Liu et al., 2017). Chemotherapy, both in adjuvant and neoadjuvant settings, has remained the treatment of choice for most patients with PDAC. However, it has not been helpful in a significant improvement of survival of these patients. This leaves surgery as the only curative option but fewer than $20 \%$ of patients present with a resectable disease at diagnosis (DeWitt et al., 2004). The unavailability of a useful diagnostic and prognostic biomarker has always been a concern for PDAC (Herreros-Villanueva and Bujanda, 2016). 
PDAC could be associated with several targets including KRAS, TP53, TGF- $\beta$, WNT, NOTCH, SMAD4, CDKN2A, ARID1A, MLL3, and TGFBR2 (Bailey et al., 2016; Chou et al., 2018). Important are aberrations in BRCA and DNA repair for whom PARP-inhibitors are now an option. Small proportion $(1 \%-2 \%)$ of PDAC is also associated with microsatellite instability (MSI) (Barrett et al., 2017; Humphris et al., 2017; $\mathrm{Hu}$ et al., 2018). MSI results from mismatch repair deficiency (dMMR) and consists of repetitive 1-6 base pairs of DNA (Umar and Kunkel, 1996; Humphris et al., 2017). dMMR or loss of functional ability of any of the mismatch repair proteins (MLH1, MSH2, MSH6, and PMS2) hinders the effective DNA replication process. Research has indicated that cancers with dMMR and MSI-H respond very well to immune checkpoint inhibitors. This implies that targeting the immune checkpoints including programmed cell death-1 (PD-1) and cytotoxic T lymphocyte antigen-4 (CTLA-4) encourages T cells to fight cancer cells. This has been well-elaborated for melanoma and lung cancer, but data is lacking for PDAC.

Herein, we report a case of PDAC whose MSI-H status was identified on liquid biopsy which is also known as circulating tumor DNA (ctDNA) testing. Our patient showed a dramatic response to immunotherapy which was again assessed on ctDNA assays.

\section{CASE PRESENTATION}

Patient is an 81-year old female who had unrelenting pain in her stomach in January 2018. She had an ultrasound done by her gastroenterologist that showed a mass in the pancreatic head versus body. A follow-up CT scan confirmed the ultrasound findings and also showed one possible enlarged lymph node. This was followed up by MRI at Mayo Clinic, Florida in March 2018, which showed locally advanced pancreatic mass centered at the junction of the body and tail measuring $5.1 \times 6.4 \times 5.2 \mathrm{~cm}$. The results also showed encasement of the first jejunal arterial and venous branches with adjacent mass effect causing narrowing of the superior mesenteric vein confluence. Enlarged right common iliac artery chain lymph node measuring $1.4 \times 1.1 \mathrm{~cm}$ and indeterminate lesions in the posterior aspect of the vertebral body at T9 were noted.

A baseline ctDNA test was obtained, which is at present part of our standard of care at Mayo Clinic, Florida for patients with GI malignancies. Testing is performed through commercially available platforms. In this particular patient, this was done through Guardant360 that showed SMAD4 R361H, TP53R213L, KRAS G12D, RET A640A, KIT K412K, NTRK3 R630G, ARID1A G1711fs and the highest variant allele fraction was noted to be $2.2 \%$ as shown in Table 1 . She was started on neoadjuvant chemotherapy with gemcitabine and paclitaxel since surgery was not an option, but there was not much response in her repeat scans in May 2018, though there was a decrease in the highest variant allele fraction to $1.2 \%$. She was then switched to 5-fluorouracil with nanoliposomal irinotecan (5-FU was held due to $D P D$ heterozygosity on pharmacogenomics testing). Repeat CT scan in July 2018 showed decrease in the size of a mass in the pancreas which measures $3.4 \times 3.1 \mathrm{~cm}$ compared with $6.5 \times 5.1 \mathrm{~cm}$.
TABLE 1 | Serial circulating tumor DNA evaluation in our patient with MSI-H/ dMMR pancreatic ductal adenocarcinoma and excellent response to pembrolizumab. As noted, the circulating tumor DNA in the SMAD4 R361H mutation has gone down from $2.2 \%$ to $0 \%$.

\begin{tabular}{|c|c|c|c|c|c|c|}
\hline \multicolumn{7}{|c|}{ Serial ctDNA(liquid biopsy)testing results } \\
\hline & March & May & July & Dec & Jan & Feb \\
\hline & 2018 & 2018 & 2018 & 2018 & 2019 & 2019 \\
\hline \multicolumn{7}{|c|}{ Highest Variant Allele Fraction } \\
\hline & $2.2 \%$ & $1.2 \%$ & $0.8 \%$ & $0.7 \%$ & $0.5 \%$ & $0.4 \%$ \\
\hline \multicolumn{7}{|c|}{ Clonal Mutations } \\
\hline SMAD4 R361H & $2.2 \%$ & $0.9 \%$ & $0.6 \%$ & $0.7 \%$ & $0 \%$ & $0 \%$ \\
\hline TP53 R213L & $1.9 \%$ & $0.8 \%$ & $0.5 \%$ & $0.6 \%$ & $0 \%$ & $0 \%$ \\
\hline KRAS G12D & $1.9 \%$ & $1.2 \%$ & $0.4 \%$ & $0.4 \%$ & $0 \%$ & $0 \%$ \\
\hline RET A640A & $1.6 \%$ & $0.5 \%$ & $0.5 \%$ & $0.5 \%$ & $0 \%$ & $0 \%$ \\
\hline KIT K412K & $1.5 \%$ & $0.4 \% *$ & $0.3 \%{ }^{\star}$ & $0.6 \%$ & $0 \%$ & $0 \%$ \\
\hline NTRK3 R630G & $1.4 \%$ & $0.6 \%$ & $0.4 \%$ & $0.4 \%$ & $0 \%$ & $0 \%$ \\
\hline$A R I D 1 A$ & $1.1 \%$ & $0.8 \%$ & $0.3 \%{ }^{*}$ & $0.3 \% *$ & $0 \%$ & $0 \%$ \\
\hline \multicolumn{7}{|l|}{ G1711fs } \\
\hline \multicolumn{7}{|c|}{ Subclonal Mutations } \\
\hline MTOR I486V & $1.0 \%$ & $0.1 \%$ & $0.3 \%$ & $0.4 \% *$ & $0 \%$ & $0 \%$ \\
\hline BRCA2 & $0.9 \%$ & $1.2 \% *$ & $0.8 \%$ * & $0.5 \% *$ & $0.5 \%$ & $0.4 \%$ \\
\hline \multicolumn{7}{|l|}{ A1572T } \\
\hline HNF1A A209T & $0.9 \%$ & $0.4 \%$ & $0.4 \%$ & $0.3 \%$ & $0 \%$ & $0 \%$ \\
\hline$A R I D 1 A$ & $0.9 \%$ & $0 \%$ & $0 \%$ & $0 \%$ & $0 \%$ & $0 \%$ \\
\hline \multicolumn{7}{|l|}{ G1847G } \\
\hline DDR2 K699 & $0.7 \%$ & $0 \%$ & $0.2 \%$ & $0 \%$ & $0 \%$ & $0 \%$ \\
\hline MPL S505N & $0.5 \%$ & $0 \%$ & $0.2 \%$ & $0 \%$ & $0 \%$ & $0 \%$ \\
\hline PIK3CA W11R & $0.4 \%$ & $0 \%$ & $0 \%$ & $0.3 \%$ & $0 \%$ & $0 \%$ \\
\hline MET N1081S & $0.2 \%$ & $0 \%$ & $0 \%$ & $0.2 \%$ & $0 \%$ & $0 \%$ \\
\hline ATM G2675 & $0.2 \%$ & $0 \%$ & $0 \%$ & $0 \%$ & $0 \%$ & $0 \%$ \\
\hline EGFR E543G & $0.1 \%$ & $0 \%$ & $0 \%$ & $0 \%$ & $0 \%$ & $0 \%$ \\
\hline MSI status & ND & ND & ND & high & ND & ND \\
\hline \multirow{2}{*}{\multicolumn{7}{|c|}{ \# Concordance with tissue biopsy - clinical concordance: yes }} \\
\hline & & 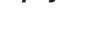 & \multicolumn{4}{|c|}{ clonal concordance: yes } \\
\hline & & & \multicolumn{4}{|c|}{ MSI-high detection: yes } \\
\hline
\end{tabular}

\begin{tabular}{|c|c|c|c|c|c|c|}
\hline Treatment & $\begin{array}{l}\text { Neoad } \\
\text { (gemci } \\
\text { 5-fluor } \\
\text { nanolip }\end{array}$ & $\begin{array}{l}\text { chen } \\
\text { and } \\
\text { I with } \\
\text { al irin }\end{array}$ & $\begin{array}{l}\text { erapy } \\
\text { taxel/ } \\
\text { an) }\end{array}$ & $\begin{array}{l}\text { Immun } \\
\text { (Pemb }\end{array}$ & $\begin{array}{l}\text { erapy } \\
\text { umak }\end{array}$ & \\
\hline Tumor mark & & & & & & \\
\hline CEA (ng/ml) & 15 & 11.4 & 16.2 & 22.1 & 8.7 & 3.3 \\
\hline $\begin{array}{l}\text { CA-19-9 } \\
\text { (Units/ml) }\end{array}$ & 5 & 4 & 6 & 6 & 7 & 6 \\
\hline
\end{tabular}

$50 \%$ of the highest variant allele fraction value has been used to differentiate clonal from sub clonal mutations. *indicates change from clonal to Subclonal and vice-versa; ND, Not Detected.

*Biomarker profiling on tissue sample detected SMAD4 R361H, KRAS G12D, ARID1A G1711fs mutations and MSI-high status. Therefore, ctDNA (liquid biopsy testing) is concordant with tissue biopsy testing in this patient.

Moreover, highest variant allele fraction dropped down to $0.8 \%$ on ctDNA testing in July 2018. Chemoradiation with capecitabine was added to her treatment plan in August 2018.

In December 2018, CT scan of the chest showed a new right lower lung lobe nodule suspicious for metastatic disease along with a persistent mass in the body of the pancreas. In the repeat ctDNA testing in December 2018, she was noted to be MSI-High/mismatch repair deficient (dMMR). Furthermore, mismatch repair immunohistochemistry on the tissue sample showed loss of 
MLH1 and PSM2 proteins. Therefore, she was considered a great candidate for immunotherapy pembrolizumab on-label and was started on it. Dramatic improvement was noticed within 4 weeks of treatment with pembrolizumab and repeat ctDNA testing in January 2019 showed loss of all the above noted mutations. Furthermore, the highest variant allele fraction dropped down to $0.5 \%$ and patient continues to be on this therapy as depicted in Figure 1.

\section{DISCUSSION}

The management of PDAC is a complex task. To begin with, tissue biopsy has been the diagnostic test of choice historically which is a cumbersome technique. Moreover, it is troublesome for the patients to have repeated serial tissue biopsies in order to monitor the response to therapy. In the past decade, liquid biopsy has emerged as a noninvasive and patient-convenient technique that has demonstrated the clinical utility and validity for various cancers. However, it has not been widely incorporated into clinical practice for the management of all types of cancers especially PDAC because of sparsity of evidence. Our case showed the promising role of liquid biopsy not only in detection of the underlying genetic aberration but also in determination of the treatment response in PDAC.
The available data on the prevalence of $\mathrm{dMMR}$ and MSI-H in PDAC is limited and heterogeneous. Previous studies have demonstrated the existence of MSI-H in PDAC, however, the findings were controversial. Yamamoto et al. investigated 103 PDAC patients and the reported incidence of MSI-H in their cohort was $16 \%$. The researchers also reported the finding of MSI$\mathrm{H}$ in $100 \%$ of their patients with hereditary PDAC $(n=3)$ (Yamamoto et al., 2001). Goggins et al. studied 82 xenografts of pancreatic carcinoma and reported that $3.7 \%$ of their specimens had MSI-H (Goggins et al., 1998). Ouyang et al. investigated 60 pancreatic cancer patients and found MSI-H in 9 (15\%) patients of their cohort (Ouyang et al., 1998). Venkatasubbarao et al. reported the presence of MSI-H in $4(29 \%)$ out of their 14 surgically resected samples of pancreatic adenocarcinoma (Venkatasubbarao et al., 1998). Recently, $\mathrm{Hu}$ et al. investigated $833 \mathrm{PDAC}$ patients and found dMMR in 7 $(0.8 \%)$ patients of their cohort (Hu et al., 2018). The summary of studies looking at pancreatic carcinoma and MSI-H/dMMR expression are demonstrated in Table 2. The disagreement in prevalence of MSI-H in PDAC might be due to confounding factors including differences in sample sizes, test techniques and diversity of tumor histology (Macherla et al., 2018).

Our patient demonstrated a phenomenal response to immunotherapy. The tumor mutation burden pre- and posttreatment was well-picked on ctDNA assays. Recent research has highlighted the clinical utility and validity of ctDNA testing in

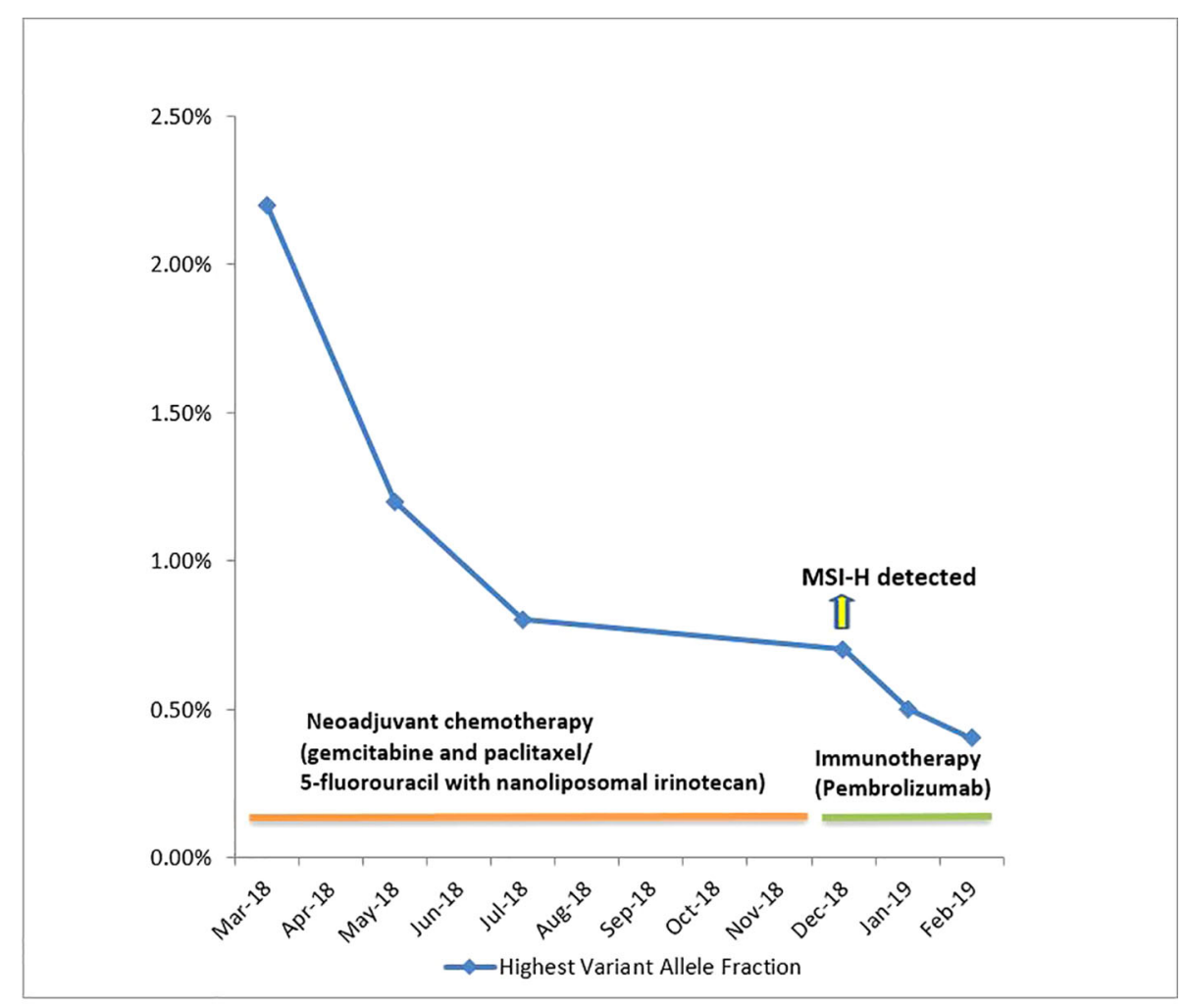

FIGURE 1 | Serial liquid biopsies and changes in Highest Variant Allele Fractions of ctDNA over the course of therapy. MSI-H detected in ctDNA testing done in December 2018. MSI-H was not detected in ctDNA reports of January 2019 and February 2019. 
TABLE 2 | Summary of studies looking at pancreatic carcinoma and MSI-H/dMMR expression.

\begin{tabular}{|c|c|c|c|c|}
\hline Study & Year & Study group & MSI/MMR status & Data source \\
\hline $\begin{array}{l}\text { Singhi et al. } \\
(2019)\end{array}$ & 2019 & 3,594 PDAC samples & MSI-H was detected in $0.5 \%$ of samples & International cohort \\
\hline Hu et al. (2018) & 2018 & 833 pancreatic adenocarcinoma patients & $\begin{array}{l}7(0.8 \%) \text { patients had dMMR, all } 7 \text { dMMR patients had } \\
\text { lynch syndrome }\end{array}$ & Multiple hospitals, USA \\
\hline $\begin{array}{l}\text { Lupinacci et al. } \\
\text { (2018) }\end{array}$ & 2018 & $\begin{array}{l}445 \text { pancreatic ductal adenocarcinoma tissue } \\
\text { samples }\end{array}$ & 1.6\% samples were dMMR & Multiple centers \\
\hline $\begin{array}{l}\text { Humphris et al. } \\
\text { (2017) }\end{array}$ & 2017 & 385 pancreatic cancer tissue samples & $1 \%$ specimens were dMMR & $\begin{array}{l}\text { Multiple centers of Australia, } \\
\text { Germany, UK and USA }\end{array}$ \\
\hline $\begin{array}{l}\text { Connor et al. } \\
(2017)\end{array}$ & 2017 & $\begin{array}{l}160 \text { pancreatic adenocarcinoma cases from } \\
154 \text { patients ( } 148 \text { primary, } 12 \text { metastases) }\end{array}$ & $\begin{array}{l}4 \text { cases were dMMR ( } 3 \text { had germline and } 1 \text { had } \\
\text { somatic mutations in MMR genes) }\end{array}$ & $\begin{array}{l}\text { International Cancer Genome } \\
\text { Consortium data portal }\end{array}$ \\
\hline Grant et al. (2015) & 2015 & $\begin{array}{l}290 \text { pancreatic ductal adenocarcinoma } \\
\text { patients }\end{array}$ & $4(1.38 \%)$ patients were dMMR & $\begin{array}{l}\text { Ontario Pancreas Cancer Study } \\
\text { (Ontario population-based registry) }\end{array}$ \\
\hline Riazy et al. (2015) & 2015 & 265 pancreatic ductal adenocarcinoma cases & 41 (15\%) were dMMR & Vancouver Coastal Health Region \\
\hline $\begin{array}{l}\text { Mitsuhashi et al. } \\
\text { (2015) }\end{array}$ & 2015 & $\begin{array}{l}282 \text { pancreatic ductal adenocarcinoma } \\
\text { patients }\end{array}$ & None of the patients had MSI-H & 3 hospitals database, Japan \\
\hline Liu et al. (2014) & 2014 & 36 acinar cell carcinoma of pancreas cases & 5 (14\%) patients were dMMR & Single academic center, USA \\
\hline $\begin{array}{l}\text { Ottenhof et al. } \\
\text { (2012) }\end{array}$ & 2012 & 78 pancreatic adenocarcinoma patients & $13 \%$ tumors were dMMR & $\begin{array}{l}3 \text { cancer treatment centers, } \\
\text { Netherlands }\end{array}$ \\
\hline $\begin{array}{l}\text { Maple et al. } \\
\text { (2005)) }\end{array}$ & 2005 & 35 pancreatic cancer patients & $3(8.6 \%)$ were dMMR who also had lynch syndrome & Single academic center, USA \\
\hline $\begin{array}{l}\text { Nakata et al. } \\
\text { (2003) }\end{array}$ & 2003 & 55 pancreatic carcinoma patients & 4 (7.3\%) tumors had abnormal hMS2-negative staining & $\begin{array}{l}\text { Single university medical center, } \\
\text { Japan }\end{array}$ \\
\hline $\begin{array}{l}\text { Yamamoto et al. } \\
\text { (2001) }\end{array}$ & 2001 & $\begin{array}{l}103 \text { pancreatic ductal adenocarcinoma ( } 100 \\
\text { sporadic, } 3 \text { hereditary) patients }\end{array}$ & $\begin{array}{l}13 \% \text { patients had } \mathrm{MSI}-\mathrm{H} \text { among sporadic PDAC } \\
\text { group; } 100 \% \text { of hereditary PDAC patients had MSI-H }\end{array}$ & $\begin{array}{l}\text { Single university medical center, } \\
\text { Japan }\end{array}$ \\
\hline $\begin{array}{l}\text { Goggins et al. } \\
(1998)\end{array}$ & 1998 & 82 xenografted pancreatic carcinomas & 3 (3.7\%) specimens had MSI-H & Single academic center, USA \\
\hline $\begin{array}{l}\text { Ouyang et al. } \\
\text { (1998) }\end{array}$ & 1998 & 60 pancreatic cancer patients & 9 (15\%) patients had MSI-H & Multiple hospitals, Japan \\
\hline $\begin{array}{l}\text { Venkatasubbarao } \\
\text { et al. (1998) }\end{array}$ & 1998 & $\begin{array}{l}14 \text { surgically resected pancreatic } \\
\text { adenocarcinoma tissue samples }\end{array}$ & 4 (29\%) had MSI-H & $\begin{array}{l}\text { Single university medical center, } \\
\text { USA }\end{array}$ \\
\hline
\end{tabular}

the management of various gastrointestinal cancers including PDAC (Shahjehan et al., 2019). Our findings also suggest that serial monitoring of tumor mutation burden can serve as a potential prognostic biomarker in pancreatic cancer. Previously, this was not feasible before the implication of ctDNA testing. The advent of immune checkpoint inhibitors has revolutionized the management of various MSI-H/dMMR tumors especially non-small cell lung carcinoma and melanoma. In May 2017, the United States Food and Drug Administration (FDA) approved pembrolizumab, a PD-1 inhibitor, for the treatment of MSI-H/dMMR solid tumors regardless of site of origin or histology that didn't respond or have metastasized after the introduction of first line agents (Lemery et al., 2017). The role of immunotherapy in PDAC has been studied in various clinical trials, however, no objective/complete response was achieved (Brahmer et al., 2012; Patnaik et al., 2015). The potential factors responsible for resistance of PDAC to immunotherapy could be low immunogenicity, decreased tumor mutation burden and inherent quality of being unlikely to be detected by the immune system (Evans et al., 2016).

There are several ongoing clinical trials that are investigating the role of various anti-PD-1/PD-L1 agents including pembrolizumab, nivolumab, etc. as monotherapy as well as combination regimens in PDAC. A recent phase I study investigated the role of a combination regimen consisting of a tumor-associated macrophage-targeting agent cabiralizumab and the anti-PD-1 nivolumab in metastatic PDAC. The combination regimen demonstrated a confirmed objective response in 4 of 31 (13\%) patients. The researchers also revealed that all of these 4 patients with confirmed objective response had MSI-H and didn't show response to anti-PD-1 or PD-L1 monotherapy (NCT02526017) (Wainberg ZA et al., 2017).

Le et al. investigated the efficacy of PD-1 blockade in the management of 12 types of solid tumors including pancreatic cancer in a multicenter phase 2 study. They enrolled all dMMR cancer patients $(n=86)$ who had at least one prior therapy and developed a progressive disease. The estimated objective and complete response rates were $53 \%$ and $21 \%$, respectively. Of note, the subset analysis for pancreatic cancer $(n=8)$ demonstrated an objective response rate of $62 \%$. The researchers indicated that the complete and partial responses were attained in $2(25 \%)$ and $3(37 \%)$ pancreatic cancer patients respectively. For the colorectal cancer $(n=40)$, their results showed the objective and complete response rates of $52 \%$ and $12 \%$, respectively (NCT01876511). The study is still ongoing and manifests the value of immune checkpoint inhibitors in pancreatic cancer (Le et al., 2017).

\section{CONCLUSION AND FUTURE DIRECTIONS}

Pancreatic cancer is a lethal cancer with poor outcomes in spite of the recent breakthroughs in combination chemotherapy regimens. Immune checkpoint inhibitors have exhibited strong responses in several MSI-H solid tumors but there is lack of 
evidence regarding pancreatic cancer. Liquid biopsy could be incorporated in the management of these patients to record serial assessments of tumor mutation burden and to detect microsatellite instability, where obtaining tissue is often very difficult.

\section{DATA AVAILABILITY STATEMENT}

All datasets generated for this study are included in the article/ supplementary material.

\section{REFERENCES}

Bailey, P., Chang, D. K., Nones, K., Johns, A. L., Patch, A.-M., and Gingras, M.-C. (2016). Genomic analyses identify molecular subtypes of pancreatic cancer. Nature 531 (7592), 47-52. doi: 10.1038/nature16965

Barrett, M. T., Deiotte, R., Lenkiewicz, E., Malasi, S., Holley, T., and Evers, L. (2017). Clinical study of genomic drivers in pancreatic ductal adenocarcinoma. Br. J. Cancer 117 (4), 572-582. doi: 10.1038/bjc.2017.209

Brahmer, J. R., Tykodi, S. S., Chow, L. Q., Hwu, W. J., Topalian, S. L., and Hwu, P. (2012). Safety and activity of anti-PD-L1 antibody in patients with advanced cancer. N. Engl. J. Med. 366 (26), 2455-2465. doi: 10.1056/NEJMoa1200694

Chou, A., Froio, D., Nagrial, A. M., Parkin, A., Murphy, K. J., and Chin, V. T. (2018). Tailored first-line and second-line CDK4-targeting treatment combinations in mouse models of pancreatic cancer. Gut 67 (12), 21422155. doi: 10.1136/gutjnl-2017-315144

Connor, A. A., Denroche, R. E., Jang, G. H., Timms, L., Kalimuthu, S. N., and Selander, I. (2017). Association of distinct mutational signatures with correlates of increased immune activity in pancreatic ductal adenocarcinoma. JAMA Oncol. 3 (6), 774-783. doi: 10.1001/ jamaoncol.2016.3916

DeWitt, J., Devereaux, B., Chriswell, M., McGreevy, K., Howard, T., and Imperiale, T. F. (2004). Comparison of endoscopic ultrasonography and multidetector computed tomography for detecting and staging pancreatic cancer. Ann. Intern. Med. 141 (10), 753-763. doi: 10.7326/0003-4819-141-10-200411160-00006

Erkan, M., Reiser-Erkan, C., Michalski, C. W., and Kleeff, J. (2010). Tumor microenvironment and progression of pancreatic cancer. Exp. Oncol. 32 (3), $128-131$.

Erkan, M., Reiser-Erkan, C., Michalski, C. W., Kong, B., Esposito, I., Friess, H., et al. (2012). The impact of the activated stroma on pancreatic ductal adenocarcinoma biology and therapy resistance. Curr. Mol. Med. 12 (3), 288-303. doi: 10.2174/156652412799218921

Evans, M. S., Diamond, M. S., Rech, A. J., Chao, T., Richardson, M. W., and Lin, J. H. (2016). Lack of immunoediting in murine pancreatic cancer reversed with neoantigen. JCI Insight 1 (14). doi: 10.1172/jci.insight.88328

Goggins, M., Offerhaus, G. J., Hilgers, W., Griffin, C. A., Shekher, M., and Tang, D.. (1998). Pancreatic adenocarcinomas with DNA replication errors (RER+) are associated with wild-type K-ras and characteristic histopathology. poor differentiation, a syncytial growth pattern, and pushing borders suggest RER+. Am. J. Pathol. 152 (6), 1501-1507.

Grant, R. C., Selander, I., Connor, A. A., Selvarajah, S., Borgida, A., and Briollais, L. (2015). Prevalence of germline mutations in cancer predisposition genes in patients with pancreatic cancer. Gastroenterology 148 (3), 556-564. doi: 10.1053/j.gastro.2014.11.042

Hackeng, W. M., Hruban, R. H., Offerhaus, G. J., and Brosens, L. A. (2016). Surgical and molecular pathology of pancreatic neoplasms. Diagn. Pathol. 11 (1), 47. doi: 10.1186/s13000-016-0497-z

Herreros-Villanueva, M., and Bujanda, L. (2016). Non-invasive biomarkers in pancreatic cancer diagnosis: what we need versus what we have. Ann. Transl. Med. 4 (7), 134. doi: 10.21037/atm.2016.03.44

Hu, Z. I., Shia, J., Stadler, Z. K., Varghese, A. M., Capanu, M., and Salo-Mullen, E. (2018). Evaluating mismatch repair deficiency in pancreatic adenocarcinoma:

\section{ETHICS STATEMENT}

Written informed consent was obtained from the patient for the publication of this case report.

\section{AUTHOR CONTRIBUTIONS}

SK and FS drafted the initial draft manuscript with guidance from PK. Author PK revised the manuscript and further edited by all the authors. All authors approved the final draft for publication.

challenges and recommendations. Clin. Cancer Res. 24 (6), 1326-1336. doi: 10.1158/1078-0432.CCR-17-3099

Humphris, J. L., Patch, A. M., Nones, K., Bailey, P. J., Johns, A. L., and McKay, S. (2017). Hypermutation in pancreatic cancer. Gastroenterology 152 (1), 6874.e2. doi: 10.1053 /j.gastro.2016.09.060

Le, D. T., Durham, J. N., Smith, K. N., Wang, H., Bartlett, B. R., and Aulakh. (2017). Mismatch repair deficiency predicts response of solid tumors to PD-1 blockade. Science 357 (6349), 409-413. doi: 10.1126/science.aan6733

Lemery, S., Keegan, P., and Pazdur, R. (2017). First FDA approval agnostic of cancer site - when a biomarker defines the indication. N. Engl. J. Med. 377 (15), 1409-1412. doi: 10.1056/NEJMp1709968

Liu, W., Shia, J., Gönen, M., Lowery, M. A., O'Reilly, E. M., and Klimstra, D. S. (2014). DNA mismatch repair abnormalities in acinar cell carcinoma of the pancreas: frequency and clinical significance. Pancreas 43 (8), 1264-1270. doi: 10.1097/MPA.0000000000000190

Liu, Q., Liao, Q., and Zhao, Y. (2017). Chemotherapy and tumor microenvironment of pancreatic cancer. Cancer Cell Int. 17, p. 68. doi: 10.1186/s12935-017-0437-3

Lupinacci, R. M., Goloudina, A., Buhard, O., Bachet, J. B., Maréchal, R., and Demetter, P. (2018). Prevalence of microsatellite instability in intraductal papillary mucinous neoplasms of the pancreas. Gastroenterology 154 (4), 1061-1065. doi: 10.1053/j.gastro.2017.11.009

Macherla, S., Laks, S., Naqash, A. R., Bulumulle, A., Zervos, E., and Muzaffar, M. (2018). Emerging Role of Immune Checkpoint Blockade in Pancreatic Cancer. Int. J. Mol. Sci. 19 (11). doi: 10.3390/ijms19113505

Mahadevan, D., and Von Hoff, D. D. (2007). Tumor-stroma interactions in pancreatic ductal adenocarcinoma. Mol. Cancer Ther. 6 (4), 1186-1197. doi: 10.1158/1535-7163.MCT-06-0686

Maple, J. T., Smyrk, T. C., Boardman, L. A., Johnson, R. A., Thibodeau, S. N., and Chari, S. T. (2005). Defective DNA mismatch repair in long-term ( $>$ or $=3$ years) survivors with pancreatic cancer. Pancreatology 5 (2-3), 220-7; discussion 227-8. doi: 10.1159/000085275

Mitsuhashi, K., Nosho, K., Sukawa, Y., Matsunaga, Y., Ito, M., and Kurihara, H. (2015). Association of Fusobacterium species in pancreatic cancer tissues with molecular features and prognosis. Oncotarget 6 (9), 7209-7220. doi: 10.18632/ oncotarget.3109

Nakata, B., Wang, Y. Q., Yashiro, M., Ohira, M., Ishikawa, T., Nishino, H., et al. (2003). Negative hMSH2 protein expression in pancreatic carcinoma may predict a better prognosis of patients. Oncol. Rep. 10 (4), 997-1000. doi: 10.3892/or.10.4.997

Ottenhof, N. A., Morsink, F. H., Ten Kate, F., van Noorden, C. J., and Offerhaus, G. J. (2012). Multivariate analysis of immunohistochemical evaluation of protein expression in pancreatic ductal adenocarcinoma reveals prognostic significance for persistent Smad4 expression only. Cell Oncol. (Dordr) 35 (2), 119-126. doi: 10.1007/s13402-012-0072-x

Ouyang, H., Furukawa, T., Abe, T., Kato, Y., and Horii, A. (1998). The BAX gene, the promoter of apoptosis, is mutated in genetically unstable cancers of the colorectum, stomach, and endometrium. Clin. Cancer Res. 4 (4), 1071-1074.

Patnaik, A., Kang, S. P., Rasco, D., Papadopoulos, K. P., Elassaiss-Schaap, J., and Beeram, M. (2015). Phase I study of pembrolizumab (MK-3475; Anti-PD-1 monoclonal antibody) in patients with advanced solid tumors. Clin. Cancer Res. 21 (19), 4286-4293. doi: 10.1158/1078-0432.CCR-14-2607 
Riazy, M., Kalloger, S. E., Sheffield, B. S., Peixoto, R. D., Li-Chang, H. H., and Scudamore, C. H. (2015). Mismatch repair status may predict response to adjuvant chemotherapy in resectable pancreatic ductal adenocarcinoma. Mod. Pathol. 28 (10), 1383-1389. doi: 10.1038/modpathol.2015.89

Ryerson, A. B., Eheman, C. R., Altekruse, S. F., Ward, J. W., Jemal, A., and Sherman, R. L. (2016). Annual report to the nation on the status of cancer, 1975-2012, featuring the increasing incidence of liver cancer. Cancer 122 (9), 1312-1337. doi: 10.1002/cncr.29936

Shahjehan, F., Kamatham, S., and Kasi, P. M. (2019). Role of circulating tumor dna in gastrointestinal cancers: update from abstracts and sessions at ASCO 2018. Front. Oncol. 9, 358-358. doi: 10.3389/fonc.2019.00358

Siegel, R. L., Miller, K. D., and Jemal, A. (2019). Cancer statistics, 2019. CA Cancer J. Clin. 69 (1), 7-34. doi: 10.3322/caac.21551

Singhi, A. D., George, B., Greenbowe, J. R., Chung, J., Suh, J., and Maitra, A. (2019). Real-time targeted genome profile analysis of pancreatic ductal adenocarcinomas identifies genetic alterations that might be targeted with existing drugs or used as biomarkers. Gastroenterology 156 (8), 2242-2253.e4. doi: 10.1053 /j.gastro.2019.02.037

Umar, A., and Kunkel, T. A. (1996). DNA-replication fidelity, mismatch repair and genome instability in cancer cells. Eur. J. Biochem. 238 (2), 297-307. doi: 10.1111/j.1432-1033.1996.0297z.x

Venkatasubbarao, K., Ahmed, M. M., Swiderski, C., Harp, C., Lee, E. Y., McGrath, P., et al. (1998). Novel mutations in the polyadenine tract of the transforming growth factor beta type II receptor gene are found in a subpopulation of human pancreatic adenocarcinomas. Genes Chromosomes
Cancer 22 (2), 138-144. doi: 10.1002/(SICI)1098-2264(199806)22:2<138::AIDGCC8>3.0.CO;2-Y

Wainberg, Z. A., Piha-Paul, S. A., Luke, J., Kim, E. J., Thompson, J. A., and Britten, C. D. (2017). First-in-human phase 1 dose-escalation and expansion of a novel combination, anti-CSF-1 receptor (cabiralizumab) plus anti-PD-1 (nivolumab), in patients with advanced solid tumors. In 2017 Annual Meeting of the Society for Immunotherapy of Cancer. National Harbor, MD.

Yachida, S., and Iacobuzio-Donahue, C. A. (2009). The pathology and genetics of metastatic pancreatic cancer. Arch. Pathol. Lab. Med. 133 (3), 413-422. doi: 10.1043/1543-2165-133.3.413

Yamamoto, H., Itoh, F., Nakamura, H., Fukushima, H., Sasaki, S., Perucho, M., et al. (2001). Genetic and clinical features of human pancreatic ductal adenocarcinomas with widespread microsatellite instability. Cancer Res. 61 (7), 3139-3144.

Conflict of Interest: The authors declare that the research was conducted in the absence of any commercial or financial relationships that could be construed as a potential conflict of interest.

Copyright (c) 2020 Kamatham, Shahjehan and Kasi. This is an open-access article distributed under the terms of the Creative Commons Attribution License (CC BY). The use, distribution or reproduction in other forums is permitted, provided the original author(s) and the copyright owner(s) are credited and that the original publication in this journal is cited, in accordance with accepted academic practice. No use, distribution or reproduction is permitted which does not comply with these terms. 